\title{
Determination of the Antioxidant Capacity of Red Fruits by Miniaturized Spectrophotometry Assays
}

\author{
Magda M. Becker, ${ }^{\circledR *, a, b}$ Gilvanda S. Nunes, ${ }^{b, c, d}$ Danilo B. Ribeiro, ${ }^{c}$ \\ Francisco E. P. S. Silva, ${ }^{d}$ Gaëlle Catanante ${ }^{a}$ and Jean-Louis Marty ${ }^{a}$ \\ ${ }^{a}$ BAE-LBBM, Bât. S, University of Perpignan, 52 avenue Paul Alduy, \\ 66860 Perpignan Cedex, France \\ ${ }^{b}$ Programa de Doutorado em Biodiversidade e Biotecnologia, Bionorte, \\ Universidade Federal do Maranhão (UFMA), Avenida dos Portugueses, 1966, \\ Bacanga, 65080-805 São Luís-MA, Brazil \\ 'Programa de Pós-Graduação em Química, Universidade Federal do Maranhão (UFMA), \\ Avenida dos Portugueses, 1966, Bacanga, 65080-805 São Luís-MA, Brazil \\ ${ }^{d}$ Programa de Pós-Graduação em Biodiversidade e Conservação, \\ Universidade Federal do Maranhão (UFMA), Avenida dos Portugueses, 1966, \\ Bacanga, 65080-805 São Luís-MA, Brazil
}

\begin{abstract}
Natural sources with high antioxidant capacity represent an interesting potential to prevent or minimize the oxidative stress that causes many chronic diseases. The antioxidant capacity of red fruits (strawberry and cherry) was evaluated by miniaturized spectrophotometric methods 2,2'-azino-bis(3-ethylbenzthiazoline-6-sulfonic acid) (ABTS), 2,2-diphenyl-1-picrylhydrazyl (DPPH) and nitroblue tetrazolium (NBT). ABTS and DPPH colorimetric methods are based on the ability of antioxidants to scavenge synthetic free radicals produced in vitro, which have a different chemical structure from the natural reactive oxygen species generated in the human body. In this respect, the NBT method stands up because it is based on $\mathrm{O}_{2}^{--}$scavenging which is generated in vitro by enzymatic reaction systems. The spectrophotometric assays adapted on microtiter plates allowed a rapid, inexpensive and simultaneous analysis. Larger amounts of lipophilic and hydrophilic antioxidants were obtained from strawberry fruit, which showed the lowest $50 \%$ signal inhibition concentration $\left(\mathrm{IC}_{50}\right)$ values. The fruit analyzed showed promising sources of bioactive compounds with high antioxidant properties.
\end{abstract}

Keywords: antioxidant capacity, miniaturized assays, red fruits

\section{Introduction}

In the last years, there is a continuous demand for natural sources of antioxidants in order to prevent the oxidative process that has been identified as the cause of the decreasing of nutritional quality in the foodstuff, the rancidity in cosmetic products and oils, but above all, the development and progression of several human pathologies like cancer, Parkinson's and Alzheimer's. ${ }^{1,2}$

Antioxidants are any substances that, when present even at low concentrations, delay or inhibit significantly oxidation processes in living beings. This occurs due to

*e-mail: magda.becker@hotmail.com their ability to hydrogen atom transfer (HAT) and/or single electron transfer (SET) to eliminate the unpaired condition of the free radical and to chelate metals resulting from the oxidation process. ${ }^{3,4}$

Antioxidants can be classified into two major groups: enzymatic and non-enzymatic substances. Some of these compounds, that include enzymes, low-molecular-weight molecules, and enzyme cofactors, are produced endogenously. ${ }^{5}$ Many non-enzymatic antioxidants are obtained from dietary sources, such as vegetables, fruits, whole grains, wine and herbal infusions, considered sources of vitamins (A, E and C), phenolic compounds (gallic and caffeic acids, quercetin, and rutin), and minerals (Se and $\mathrm{Zn}){ }^{6,7}$ 
Due to chemical diversity of antioxidants and its behavior that may respond in a different manner to numerous radical or oxidant sources, there is not yet a unique, simple and universal method for antioxidant capacity screening, which is why the need to evaluate the antioxidant capacity of foodstuffs by different methods. ${ }^{7}$ Several traditional analytical methodologies, such as spectrophotometric, electrochemical and chromatographic ones, have been used, each one differing in relation to the mechanism of generation of radicals and/or target molecules as well as to the final detection/measurement of the reaction products. ${ }^{2}$ However, in recent years, a great effort has been done in the use of more sophisticated and precise bioanalytical methods such as those based on electrochemical sensors and biosensors, in order to improve the detection performance. ${ }^{8}$

In general, spectrophotometric techniques are simple, rapid and not expensive, which probably explains their widespread use in antioxidant screening. In turn, spectrometric techniques rely on the reaction of a radical, radical cation or complex with an antioxidant molecule capable of HAT and/or SET. ${ }^{2,9,10}$ The most common methods for the in vitro determination of antioxidant capacity in foods are based on spectrophotometric assays employing 2,2-diphenyl-1-picrylhydrazyl (DPPH), 2,2'-azino-bis(3ethylbenzthiazoline-6-sulfonic acid) (ABTS) and nitroblue tetrazolium (NBT) as chromogens, the latter being the most efficient in the physiologic point of view. ${ }^{9-11}$

$\mathrm{DPPH}^{\circ}$ and $\mathrm{ABTS}^{\circ+}$ are synthetic organic radicals with purple and blue-green colors, respectively, which can be reduced in the antioxidant presence, with the consequent decolorization (Figure 1). The antioxidant capacity can be evaluated by the decrease of absorption at certain wavelength. $2,9,10$
The DPPH and ABTS methods are based on the inhibition of synthetic-free radicals, which have a different structure to the reactive oxygen derivatives. In this perspective, NBT process is more advantageous because it evaluates the capacity for removal of superoxide radicals by antioxidants present in the sample under physiological conditions.

In NBT method, superoxide radicals $\left(\mathrm{O}_{2}^{--}\right)$and uric acid are generated in vitro by the hypoxanthine/xanthine oxidase system. The $\mathrm{O}_{2}{ }^{-}$radicals reduce the NBT reagent (yellow color) to formazan (purple color), which is measured spectrophotometrically at $560 \mathrm{~nm}$ (Figure 2). ${ }^{11}$

Considering the current upsurge of interest in the measurement of efficacy and use of natural antioxidants for applications in food technology, cosmetic industry, therapeutic, nutraceutical and medical usages, the aim of this work was to determine the antioxidant capacity by ABTS, DPPH and NBT miniaturized spectrophotometric methods in the red fruits (strawberry and cherry) and to compare the previously discussed spectrophotometry methods adapted to microplate reader.

\section{Experimental}

\section{Reagents and equipment}

Analytical grade chemicals were employed in the preparation of all solutions. Deionized water (Milli-Q, Millipore, $18.2 \mathrm{M} \Omega \mathrm{cm}$ ) was used in all experiments. Ascorbic acid (A5960), gallic acid (G7384), Folin-Ciocalteu (F9252), $\mathrm{Na}_{2} \mathrm{CO}_{3}$ (S7795), DPPH (D9132), ABTS (A1888), $\mathrm{K}_{2} \mathrm{~S}_{2} \mathrm{O}_{8}(\mathrm{P} 5592), \mathrm{NaCl}$ (S7653), $\mathrm{Na}_{2} \mathrm{HPO}_{4}(\mathrm{~S} 0876), \mathrm{KH}_{2} \mathrm{PO}_{4}$ ( $\mathrm{P} 9791), \mathrm{K}_{2} \mathrm{HPO}_{4}$ (P3786), $\mathrm{KCl}$ (P3911), ethylenediamine tetraacetic acid (EDTA, E9884), NBT (N6876), hypoxanthine (HX, H9377), xanthine oxidase (XOD) enzyme from bovine

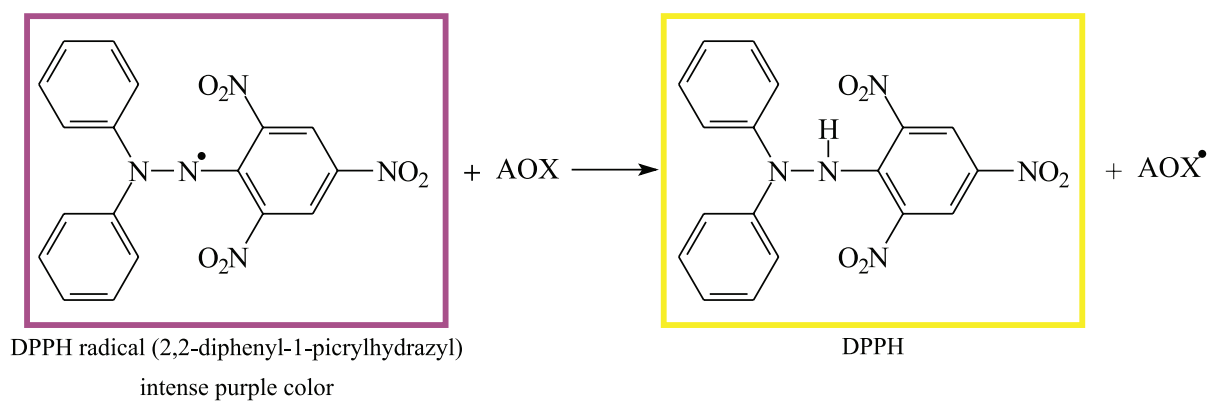

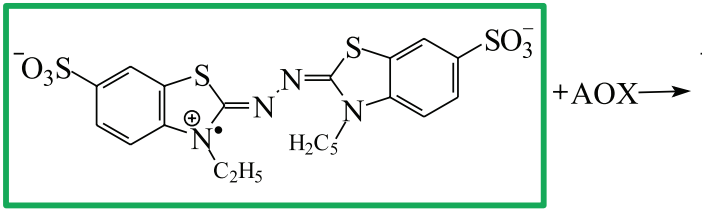

ABTS radical (2,2'-azino-bis(3-ethylbenzthiazoline-6-sulphonic acid) blue green color

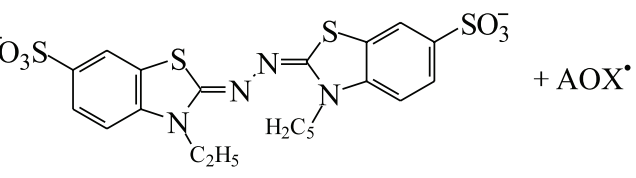

ABTS

Figure 1. Chemicals reactions involved in the DPPH and ABTS spectrophotometric assays. ${ }^{9,10}$ 


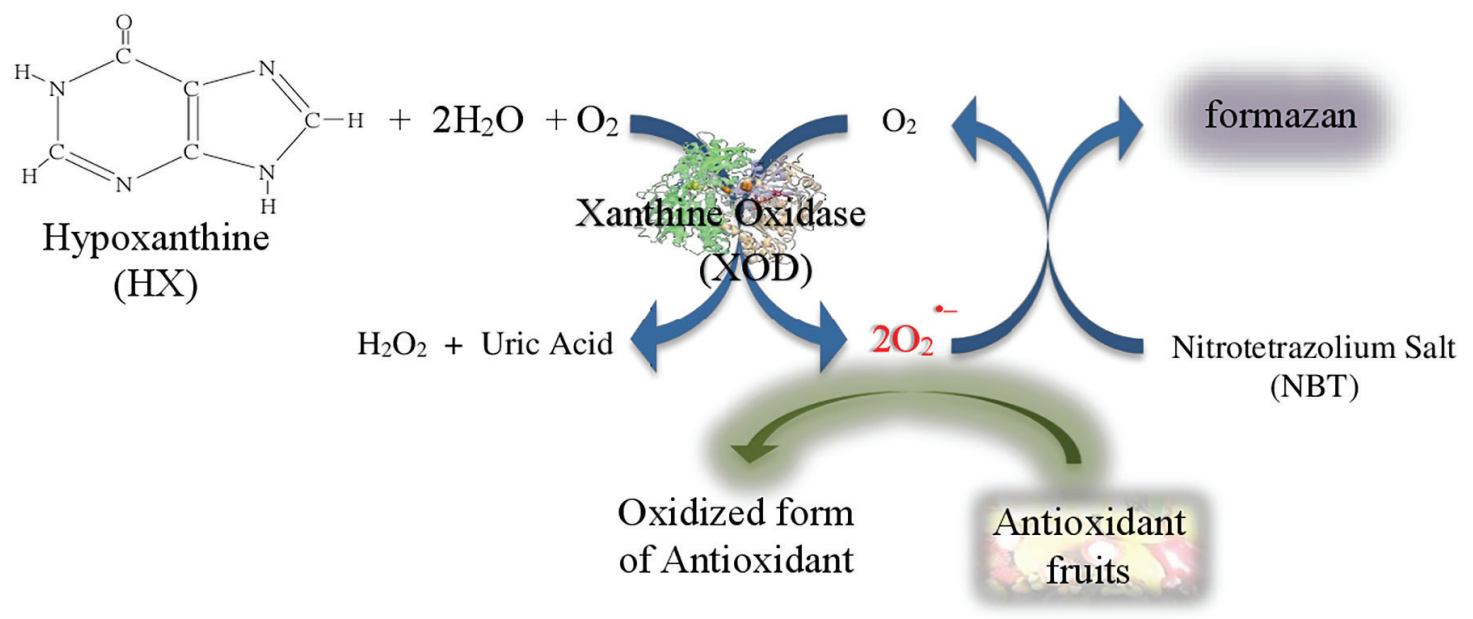

Figure 2. Reactions involved in the measurement of superoxide radical sequestration capacity using the NBT technique.

milk (X4376) were purchased from Sigma-Aldrich Corp. (Nasdaq-Sial, Darmstadt, Germany). Spectrophotometric analyses were carried out in a Multiskan Ex Primary.

\section{Sampling}

Strawberry and cherry samples presenting complete physiological maturity stage were obtained in June 2017, from a supermarket in Perpignan, France $\left(42^{\circ} 41^{\prime} 07.4^{\prime \prime} \mathrm{N}\right.$ and $\left.2^{\circ} 54^{\prime} 06.7^{\prime \prime} \mathrm{W}\right)$. The fruit samples were lyophilized at the laboratory of the University of Perpignan Via Domitia, UPVD, and allowed to stand at room temperature until analysis.

\section{Antioxidant capacity determination}

Before applying the colorimetric method, the extraction procedure had to be previously defined. So, DPPH assay was selected and the influence of time, temperature, amount of lyophilized samples and the solvent was studied. Also, the final recovery of supernatants was evaluated by comparing two different procedures: shaking and ultrasound-assisted extraction.

Better inhibitions were obtained in the extraction using $100 \mathrm{mg} \mathrm{mL}^{-1}$ of the lyophilized samples subjected to shaking for $1 \mathrm{~h}$ on a sample mixer (HulaMixer, Invitrogen Dynal AS, Life Technologies) at ca. $4{ }^{\circ} \mathrm{C}$ and protected from light. Then, the supernatant was collected after centrifugation for $10 \mathrm{~min}$ at $5000 \mathrm{rpm}$ (Hettich, Rotina $380 \mathrm{R}$ ). Lyophilized samples, in decreasing concentrations, were submitted to the miniaturized DPPH, ABTS and NBT assays.

\section{DPPH assay}

The effect of each antioxidant fruit on DPPH' radical was estimated according to recommendations of Marinova and Batchvarov ${ }^{12}$ with some modifications. All solutions were prepared in ethanol. The stock solution was prepared by dissolving $13.8 \mathrm{mg}$ DPPH with $20 \mathrm{~mL}$ ethanol and then stored until needed. The control $(100 \%)$ solution was obtained by mixing $225 \mu \mathrm{L}$ ethanol with $25 \mu \mathrm{L}$ stock solution to obtain an absorbance of $1.0 \pm 0.1$ unit at $490 \mathrm{~nm}$. Ethanolic fruit extracts $(25 \mu \mathrm{L})$ were allowed to react with $200 \mu \mathrm{L}$ of ethanol and $25 \mu \mathrm{L}$ of the DPPH solution for $20 \mathrm{~min}$ in the dark, $400 \mathrm{rpm}$, at $25^{\circ} \mathrm{C}$. Ethanol $(250 \mu \mathrm{L})$ was used for the blank control (100\%), and the ethanol $(225 \mu \mathrm{L}) /$ fruit extracts $(25 \mu \mathrm{L})$ was used as blank fruit to avoid interferences due to the sample's color. The absorbance decreasing was recorded at $490 \mathrm{~nm}$. For all evaluated assays, absorbance measurements were performed in triplicate in a microplate reader.

Different antioxidant solution concentration was evaluated to determinate the ability to scavenge DPPH ${ }^{*}$ radicals by the $50 \%$ signal inhibition concentration $\left(\mathrm{IC}_{50}\right.$ in $\mathrm{mg} \mathrm{mL}^{-1}$ that means the concentrations of samples required to scavenge $50 \%$ of free radicals), in ascorbic acid equivalents, using linear regression analysis.

A scheme review of the miniaturized DPPH assay is shown in the Figure 3.

\section{ABTS assay}

The ABTS assay was carried out according to procedure proposed by Arnao et al. ${ }^{13}$ with some modifications. Initially, a stock solution formed by $7.0 \mathrm{mmol} \mathrm{L}^{-1} \mathrm{ABTS}$ plus $2.45 \mathrm{mmol} \mathrm{L}^{-1}$ potassium persulfate solution dissolved in $10.0 \mathrm{mmol} \mathrm{L}^{-1}$ phosphate-buffered saline (PBS) buffer $(\mathrm{pH}=7.4)$ was prepared and kept during $12 \mathrm{~h}$ at room temperature and in the dark in order to allow chemical equilibrium. In order to allow the extraction of lipophilic 


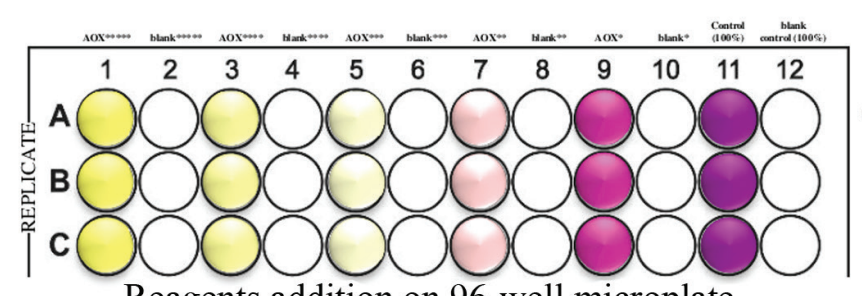

Reagents addition on 96-well microplate

Microplate proposed for the measurement of 5 different concentrations of AOX, its blank, as well as the control (100\%) and its blank

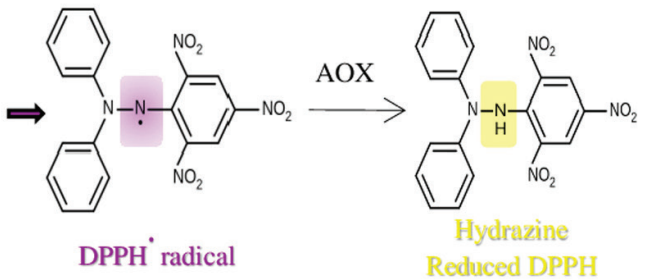

Incubation

$20 \mathrm{~min}$ reaction, $400 \mathrm{rpm}$, at $25^{\circ} \mathrm{C}$, and protection from the light

\section{Determination of the ability to scavenge $\mathrm{DPPH}^{\bullet}$ radicals}

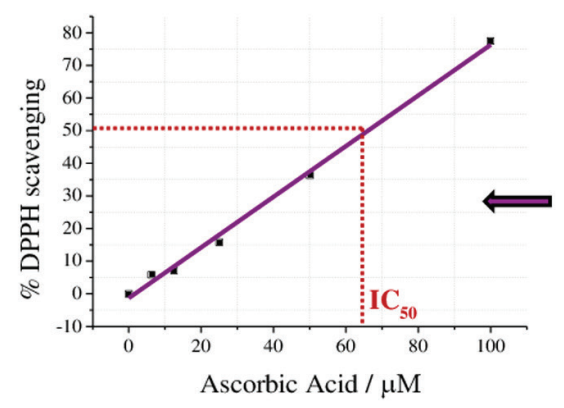

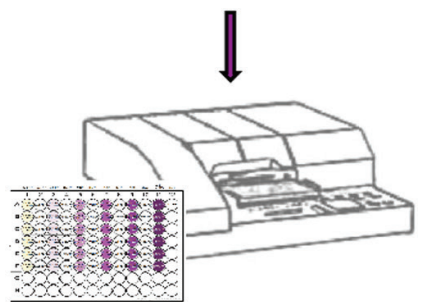

Measure at $490 \mathrm{~nm}$

Figure 3. Miniaturized DPPH assay scheme.

and hydrophilic antioxidants of the lyophilized samples, the ABTS assay was applied in three extracts of different polarities: aqueous (PBS buffer), absolute ethanol and binary extraction (1:1, hydroethanolic). The ABTS ${ }^{++}$ working solution was prepared by dilution to obtain to the control (100\%) an absorbance around 0.7 units at $405 \mathrm{~nm}$. The reaction mixture (AOX) was prepared by mixing $25 \mu \mathrm{L}$ antioxidant (fruit extracts or standard antioxidant),

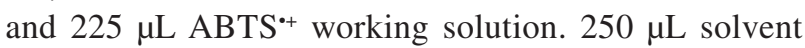
was used for the blank control $(100 \%)$, and the solvent $(225 \mu \mathrm{L}) /$ antioxidant solution $(25 \mu \mathrm{L})$ was used as blank. The decrease in absorbance after 6 min of reaction, at $25^{\circ} \mathrm{C}$, under stirring at $400 \mathrm{rpm}$ and in the dark, was recorded at $405 \mathrm{~nm}$. The ability to scavenge $\mathrm{ABTS}^{-+}$radicals was calculated by $\mathrm{IC}_{50}\left(\mathrm{mg} \mathrm{mL}^{-1}\right)$ in ascorbic acid equivalents.

\section{NBT assay}

For the NBT assay, the method proposed by CortinaPuig et al. ${ }^{11}$ was applied with some modifications. All solutions were prepared in $50 \mathrm{mmol} \mathrm{L}^{-1} \mathrm{~K}-\mathrm{PBS}(\mathrm{pH}$ 7.5) containing EDTA $\left(0.1 \mathrm{mmol} \mathrm{L}^{-1}\right)$ buffer due to the optimal enzyme conditions required. The control (100\%) was prepared by mixing $175 \mu \mathrm{L}$ K-PBS buffer, $25 \mu \mathrm{L}$ $0.75 \mathrm{mmol} \mathrm{L}^{-1} \mathrm{HX}, 25 \mu \mathrm{L} 0.75 \mathrm{mmol} \mathrm{L}^{-1} \mathrm{NBT}$, followed by the incubation step ( $5 \mathrm{~min}$, in the dark, $700 \mathrm{rpm}$, at $25^{\circ} \mathrm{C}$ ), and the addition of $25 \mu \mathrm{L} 0.70 \mathrm{U} \mathrm{mL}^{-1} \mathrm{XOD}$ to obtain after the final incubation step (15 min, in the dark, $700 \mathrm{rpm}$, at $25^{\circ} \mathrm{C}$ ) an absorbance around $0.28 \pm 0.02$ units at $560 \mathrm{~nm}$. Fruit extracts $(25 \mu \mathrm{L})$ were allowed to same reagents sequence addition but using $150 \mu \mathrm{L}$ K-PBS buffer. The blank control and blank fruit were prepared in absence of XOD and adding $25 \mu \mathrm{L}$ K-PBS buffer in order to obtain the final volume of $250 \mu \mathrm{L}$. The increase in absorbance after the final incubation step was recorded at $560 \mathrm{~nm}$. The ability to scavenge $\mathrm{O}_{2}^{-}$- radicals was calculated by $\mathrm{IC}_{50}\left(\mathrm{mg} \mathrm{mL}^{-1}\right)$ in ascorbic acid equivalents.

\section{Results and Discussion}

The antioxidant capacity results in $\mathrm{IC}_{50}$ for the different assays, in different solvents extracts, of the lyophilized red fruits are shown in Table 1. Ethanol and/or aqueous buffer were adopted as solvents in the samples antioxidants extractions after considering safety in handling, the human consumption in some food products such as beverages, wine, and liquors, as well as, the reference as a good solvent for antioxidant extraction. ${ }^{14}$

Strawberry pulp showed to have higher contents of lipophilic and hydrophilic antioxidants in view of the greater inhibition of the $\mathrm{DPPH}^{\circ}, \mathrm{ABTS}^{\circ+}$ and $\mathrm{O}_{2}{ }^{--}$radicals in all extracts, except in the ABTS assay for the ethanolic extract that showed similar results between the strawberry and cherry fruits. Comparing the $\mathrm{IC}_{50}$ value in the different solvent extractions in the ABTS method, it became evident that ethanol was not the better solvent for the extraction of the antioxidant compounds in the analyzed samples.

This study highlighted the advantages and limitations of the assays used. The ABTS method can be used in various solvents allowing the extraction of lipophilic 
Table 1. The antioxidant capacity of red fruits, on dry basis, in $\mathrm{IC}_{50}$ of the different extracts expressed as mean \pm standard deviation for $\mathrm{n}=3$

\begin{tabular}{|c|c|c|c|c|c|}
\hline \multirow{3}{*}{ Sample } & \multicolumn{5}{|c|}{$\mathrm{IC}_{50}$ value / $\left(\mathrm{mg} \mathrm{mL}^{-1}\right)$} \\
\hline & \multirow{2}{*}{$\begin{array}{l}\text { DPPH } \\
\text { ethanol }\end{array}$} & \multirow{2}{*}{$\begin{array}{c}\mathrm{O}_{2}^{--} \\
\text {K-PBS }\end{array}$} & \multicolumn{3}{|c|}{$\mathrm{ABTS}^{\cdot+}$} \\
\hline & & & Ethanol & ethanol:PBS & PBS \\
\hline Strawberry (Fragaria spp.) & $1.452 \pm 0.014$ & $0.123 \pm 0.005$ & $0.313 \pm 0.002^{\mathrm{a}}$ & $0.063 \pm 0.003$ & $0.072 \pm 0.002$ \\
\hline Cherry (Prunus cerasus) & $10.962 \pm 0.043$ & $0.294 \pm 0.004$ & $0.311 \pm 0.023^{\mathrm{a}}$ & $0.134 \pm 0.003$ & $0.261 \pm 0.004$ \\
\hline Ascorbic acid & 0.011 & 0.020 & $4.652 \times 10^{-3}$ & $1.652 \times 10^{-3}$ & $2.113 \times 10^{-3}$ \\
\hline
\end{tabular}

Means followed by the same letter in the same columns do not differ significantly from each other by the Tukey's test at the $5 \%$ probability level; $\mathrm{IC}_{50}$ : concentrations of samples required to scavenge $50 \%$ of free radicals; $\mathrm{O}_{2}^{--}$: superoxide radical; DPPH: 2,2-diphenyl-1-picrylhydrazyl; PBS: phosphatebuffered saline.

and hydrophilic antioxidants, and the better solvent system to be applied depends of the samples' antioxidant composition. The lower the $\mathrm{IC}_{50}$, the higher is the fruit antioxidant potential, in this view it can be observed that the best inhibition rates have been obtained through extraction with the binary solvent mixture, followed by the PBS extraction. On the other hand, the DPPH radical showed to be more stable, probably due to the resonance effect in their chemical structure and only soluble in the ethanolic extract. ${ }^{15}$ Superoxide anion radical $\left(\mathrm{O}_{2}{ }^{-}\right)$is one of the strongest ROS, which gets converted to other harmful ROS as well as free radicals such as hydrogen peroxide and hydroxyl radical in the cells. ${ }^{16}$ In this study, the strawberry extracts showed the highest superoxide scavenging activity.

Table 2 compares the main spectrophotometric methods, taking into account not only its biochemical principle and operational conditions, but also its effectiveness. ${ }^{7-10}$

The different methods in the literature for the antioxidant capacity determination of biological systems involve different radicals/oxidant sources, consequently more than one chemical mechanism. ${ }^{17}$ Additionally, the antioxidants chemical diversity allow different behavior to eliminate the unpaired condition of the free radical or to chelate metals. In view of this, no single assay accurately reflects the mechanism of action of all radical sources or all antioxidants in a complex system, ${ }^{9}$ consequently more than one antioxidant capacity method must be used for comparing the mode of action of crude or pure compounds. ${ }^{17,18}$

In this work three methods, DPPH, ABTS and NBT, were chosen based upon different reaction mechanisms, NBT utilizing the SET mechanism to eliminate superoxide radicals which are oxidants present in all aerobic biological systems, while the other (DPPH and ABTS) using the ability to HAT and/or SET to neutralize the $\mathrm{DPPH}^{\cdot}$ and $\mathrm{ABTS}^{-+}$synthetic radicals. ${ }^{7}$ In this view, NBT assay represents a more concise tool allowing investigators to assess a sample's antioxidant capacity against a specific, biologically relevant free radical, the superoxide radical $\left(\mathrm{O}_{2}^{-}\right)$, which is an oxygen-derived species that is potentially cytotoxic and causes damage to DNA, and therefore are related with a number of disorders such as Parkinson's disease and cancer. ${ }^{19-22}$

Table 3 summarizes a selection of research results obtained in the last four years using different extractions methodologies applied to strawberry and cherry fruits antioxidant capacity determination. The table includes

Table 2. Comparison of some spectrophotometric methods for antioxidant capacity scavenges regarding operation principle and advantages/disadvantages

\begin{tabular}{lcc}
\hline Assay & Biochemical principle & Characteristic \\
\hline DPPH & $\begin{array}{c}\text { antioxidants neutralize DPPH radicals by SET and HAT; } \\
\text { there is a decrease in absorbance over time, } \\
\text { proportional to the antioxidant capacity }\end{array}$ & $\begin{array}{c}\text { relatively stable radical; highly reproducible and precise; } \\
\text { applied only in organic solvents; easy and fast }\end{array}$ \\
\hline ABTS & $\begin{array}{c}\text { antioxidants neutralize ABTS } \\
\text { there is a decrease in absorbance over time, } \\
\text { proportional to the antioxidant capacity }\end{array}$ & $\begin{array}{c}\text { wide pH range; applied to hydrophilic and lipophilic antioxidants; } \\
\text { long reaction time ( }>\text { 6 min) could give incorrect results due to } \\
\text { short assay; sensitive, easy and fast }\end{array}$ \\
\hline NBT & $\begin{array}{c}\text { antioxidants neutralize } \mathrm{O}_{2}^{--} \text {radicals by SET; there is a decrease in } \\
\text { absorbance over time, proportional to the antioxidant capacity }\end{array}$ & $\begin{array}{c}\text { applied only to hydrophilic antioxidants, and in physiological } \\
\text { conditions (pH/salinity); highly reproducible, easy and fast }\end{array}$ \\
\hline
\end{tabular}

DPPH: 2,2-diphenyl-1-picrylhydrazyl; ABTS: 2'-azino-bis(3-ethylbenzthiazoline-6-sulfonic acid; NBT: nitroblue tetrazolium; HAT: hydrogen atom transfer; SET: single electron transfer. 
Table 3. Extraction conditions and results obtained from a selection of studies. Extraction conditions: solvent (volume \%, the rest up to $100 \%$ is water unless indicated), solid-to-liquid ratio, temperature, extraction time

\begin{tabular}{|c|c|c|}
\hline Extraction condition & Radical scavenging assay & Reference \\
\hline \multicolumn{3}{|c|}{ Cherry (Prunus cerasus) } \\
\hline Solvent extraction: ethanol ( $42.39 \%$, acidified $1 \%$ formic acid), $1: 15,40{ }^{\circ} \mathrm{C}, 75 \mathrm{~min}$ & ABTS: $59.61 \mathrm{mM}$ trolox $\mathrm{mL}^{-1}$ & 23 \\
\hline Ultrasound assisted extraction: ethanol ( $40 \%), 1: 15,37 \mathrm{khz}, 40^{\circ} \mathrm{C}, 40 \mathrm{~min}$ & ABTS: $105.87 \mathrm{mM}$ trolox $\mathrm{mL}^{-1}$ & 23 \\
\hline \multicolumn{3}{|c|}{ Strawberry (Fragaria spp.) } \\
\hline Solvent extraction: absolute ethanol, $1: 20,60^{\circ} \mathrm{C}$, overnight & DPPH: $\left(\mathrm{IC}_{50}\right) 39.01 \mathrm{mg} \mathrm{mL}^{-1}$ & 24 \\
\hline Ultrasound assisted extraction: ethanol:water: $\mathrm{HCl}(70: 29: 1), 1: 10,30^{\circ} \mathrm{C}, 2 \mathrm{~h}$ & DPPH: $4250 \mu \mathrm{mol}$ trolox equivalent $\mathrm{g}$ extract weight ${ }^{-1}$ & 25 \\
\hline Solvent extraction: ethanol (95\%), 1:4, at room temperature, 2 days & $\begin{array}{l}\text { DPPH: }\left(\mathrm{IC}_{50}\right) 3.1 \mu \mathrm{g} \mathrm{mL}^{-1} \\
\text { ABTS: }\left(\mathrm{IC}_{50}\right) 9.9 \mu \mathrm{g} \mathrm{mL}^{-1}\end{array}$ & 16 \\
\hline
\end{tabular}

ABTS: 2'-azino-bis(3-ethylbenzthiazoline-6-sulfonic acid; DPPH: 2,2-diphenyl-1-picrylhydrazyl; $\mathrm{IC}_{50}$ : concentrations of samples required to scavenge $50 \%$ of free radicals.

the extraction conditions, results of radical scavenging assays, and the local sampling. A comparison between the results obtained from the antioxidant capacity and those reported in the literature is complex due to the samples and sampling conditions (climate, soil composition, varieties and cultivar), as well as different methods of extraction that significantly influence the results, radical final concentration used, and different ways in which the results are presented: different reference antioxidants are employed to express the results (usually gallic acid, trolox, ascorbic acid), numerous ways of expressing the results are used, such as percent inhibition of radical for a given concentration of the sample, mass equivalent of a reference antioxidant per gram of mass of the sample or extract, $\mathrm{IC}_{50}$, among others. The standardization is longed for unifying quantities and units.

Despite the complexity, the strawberry antioxidant capacity was higher than those reported for Mandave et al..$^{24}$ for DPPH method, and lower than Basu and Maier ${ }^{16}$ for DPPH and ABTS methods. In the other cases, unfortunately, no comparison can be made between our results and the literature used.

In this work, it was evidenced that the microtiteradapted assays have allowed easy and fast analysis of numerous small samples at the same time. The plates' standardized dimensions make them ideal for automation and do not require special equipment. Moreover, their relatively small sample volumes, as well as the high densities, provide advantages in terms of reagent volume usage, cost and speed.

\section{Conclusions}

Because of the chemical heterogeneity of exogenous antioxidant compounds that may respond using more than one chemical mechanism to different sources of radicals or oxidants, there is still no universal method that can be employed. In view of this, there are different methods in the literature for the determination of the antioxidant capacity of biological systems and no assay accurately reflects the mechanism of action of all the oxidants sources or all the antioxidants in a complex system. This has led to a certain consensus of the researchers of the need to employ more than one method to determine the antioxidant capacity in order to compare the mode of action and obtain a more complete response.

DPPH, ABTS and NBT assays adapted on microtiter plates were applied to determinate the antioxidant capacity of two red fruits. The miniaturized assays have allowed rapid, inexpensive, and simultaneous analysis of the antioxidant potential of several red fruit samples. All three methods showed advantages and disadvantages inherent in the nature of the oxidizing source used and therefore of biological relevance, analytical performance (reproducibility, precision, sensitivity, response time) and solubility in solvents of different polarities. The choice of these methods should be made strictly according to the types of antioxidants to be tested.

This study is an important contribution for the food analysis area, since it will serve as a basis for the analyst to choose the best method to be used in evaluating the nutritional property of food sources.

\section{Acknowledgments}

This work was supported by the CAPES/Doctoral Sandwich Program Abroad (No. 88881.133624/201601); and the FAPEMA/Scholarship Abroad (No. BESTEXT-07273/16). 


\section{References}

1. Bouayed, J.; Bohn, T.; Oxid. Med. Cell. Longevity 2010, 3, 228.

2. Pisoschi, A. M.; Negulescu, G. P.; Biochem. Anal. Biochem. 2011, 1, DOI: 10.4172/2161-1009.1000106.

3. Flora, S. J. S.; Oxid. Med. Cell. Longevity 2009, 2, 191.

4. Lü, J.-M.; Lin, P. H.; Yao, Q.; Chen, C.; J. Cell. Mol. Med. 2010, 14,840 .

5. Bunaciu, A. A.; Aboul-Enein, H. Y.; Fleschin, S.; Applied Spectroscopy Reviews 2012, 47, 245.

6. Xu, D-P.; Li, Y.; Meng, X.; Zhou, T.; Zhou, Y.; Zheng, J.; Zhang, J-J.; Li, H-B.; Int. J. Mol. Sci. 2017, 18, 96.

7. Bhattacharyya, A.; Chattopadhyay, R.; Mitra, S.; Crowe, S. E.; Physiol Rev. 2014, 94, 329.

8. Lates, V.; Marty, J. L.; Popescu, I. C.; Electroanalysis 2011, 23, 728.

9. Prior, R. L.; Wu, X.; Schaich, K.; J. Agric. Food Chem. 2005, 53, 4290.

10. Singh, S.; Singh, R. P.; Food Rev. Int. 2008, 24, 392.

11. Cortina-Puig, M.; Muñoz-Berbel, X.; Rouillon, R.; CalasBlanchard, C.; Marty, J. L.; Bioelectrochemistry 2009, 76, 76.

12. Marinova, G.; Batchvarov, V.; J. Agric. Sci. 2011, 17, 11.

13. Arnao, M. B.; Cano, A.; Acosta, M.; Food Chem. 2001, 73, 239.

14. Sultana, B.; Anwar, F.; Przybylski, R.; Food Chem. 2007, 104, 1106.
15. Kedare, S. B.; Singh, R. P.; J. Food Sci Technol. 2011, 48, 412.

16. Basu, P.; Maier, C.; Pharmacogn. Res. 2016, 8, 258.

17. Shalaby, E. A.; Shanab, S. M.; Afr. J. Pharm. Pharmacol. 2013, 7, 528 .

18. Moharram, H. A.; Youssef, M. M.; Alexandria J. Food Sci. Technol. 2014, 11, 31.

19. Vanella, A.; di Giamoco, C.; Sorrenti, V.; Russo, A.; Castorina, C.; Campisi, A.; Renis, M.; Perez-Polo, J. R.; Neurochem. Res. 1993, 18, 1337.

20. Kontos, H. A.; Wei, E. P.; J. Neurosurg. 1986, 64, 803.

21. Birnboim, H. C.; Carcinogenesis 1986, 7, 1511.

22. Khodade, V. S.; Sharath, C. M.; Banerjee, A.; Lahiri, S.; Pulipeta, M.; Rangarajan, R.; Chakrapani, H.; ACS Med. Chem. Lett. 2014, 5, 777.

23. Demirdoven, A.; Karabiyikli, S.; Tokatli, K.; Oncul, N.; Food Sci. Technol. 2015, 63, 8 .

24. Mandave, P. C.; Pawar, P. K.; Ranjekar, P. K.; Mantri, N.; Kuvalekar, A. A.; Sci. Hortic. 2014, 172, 124.

25. Wang, Y.; Zhao, L.; Wang, D.; Huo, Y.; Ji, B.; J. Sci. Food Agric. 2016, 96, 2494.

Submitted: September 4, 2018 Published online: January 8, 2019 